\title{
Inlet Channel for a Ducted Fan Propulsion System of a Light Aircraft
}

\author{
E. Ritschl, R. Theiner, D. Hanus
}

So-called "cold-jet" propulsion units consist of a piston engine, a blower and the necessary air duct. Till now, all attempts to utilize "cold-jet" propulsion units to maintain the thrust of an airplane have been unsuccessful. Analysis has shown that the main difficulty is the deformation of the flow field at the entry to the blower [1].

Keywords: aircraft, ducted fan, cold-jet, inlet channel, aerodynamics.

\section{Introduction}

The department of Aircraft Engineering at the Czech Technical University in Prague is developing a light aircraft powered by a ducted fan ("cold-jet") propulsion unit. The plane is a replica of the well-known Czech L-39 training jet plane. A drawing of the airplane is depicted in Fig. 1.

\section{Main technical data}

Two-tandem seated, low wing monoplane, all composite aircraft.

Dimensions:

Wing span :

$7.2 \mathrm{~m}$

Wing section

MS 03XX

Length:

$7.34 \mathrm{~m}$

Height:

$3.0 \mathrm{~m}$

Wing area:

$8.5 \mathrm{~m}^{2}$

Weight empty/take-off: $280 \mathrm{~kg} / 450 \mathrm{~kg}$

Motor performance:
The proposed aircraft will be certificated in the Very Light or Micro-light (Ultra-light) aircraft category. Hence, the maximum take-off weight must be less than $450 \mathrm{~kg}$ (including two pilots). The structure of the aircraft is made at composite materials.

Previous unsuccessful attempts to utilize a "cold jet" power unit in an airplane structure showed the crucial lack of effective power output of such a propulsion unit. The problem of the Micro-light or Ultra-light Aircraft category is the strict restriction on maximum airplane weight. Usually, the utilization of a more powerful engine substantially increases the weight of the plane structure. Analysis of engines used nowadays for the Micro-light Aircraft category shows that their effective power output is insufficient for "cold jet" propulsion of a small aircraft.

The problem of the necessary power output for our engine was solved by using a Yamaha YZF-R1 motorcycle piston engine. The engine of the Yamaha YZF-R1 is derived from a motorcycle racing engine and its performance to weight ratio is 2.5. The maximum performance of the Yamaha YZF-R1 engine is $110 \mathrm{~kW}$. In addition, neither a reducer nor a built-in engine gearbox is necessary for propulsion of the ducted fan.

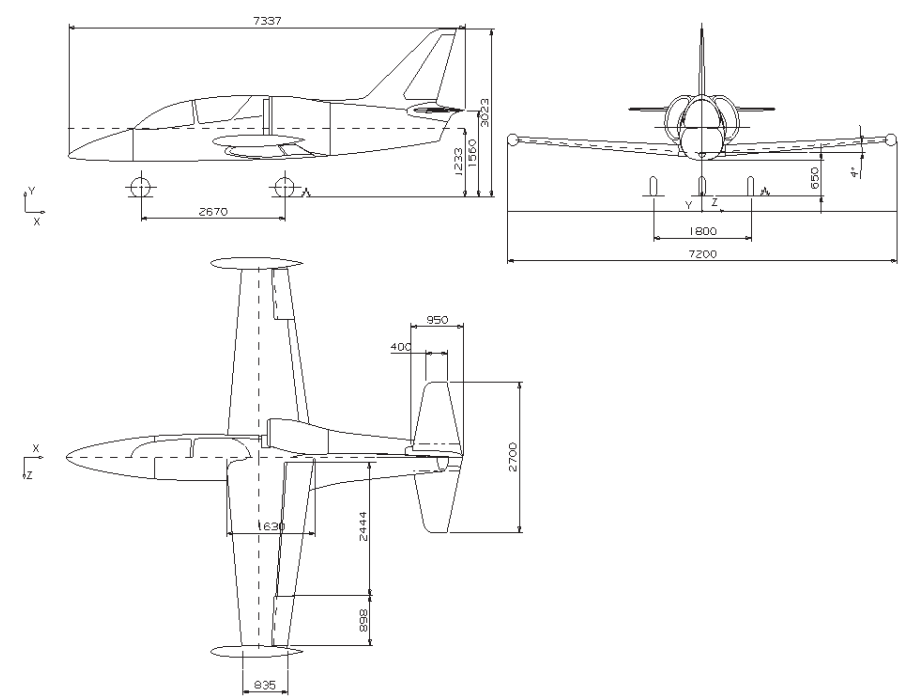

Fig. 1: Drawing of the L-39 replica 


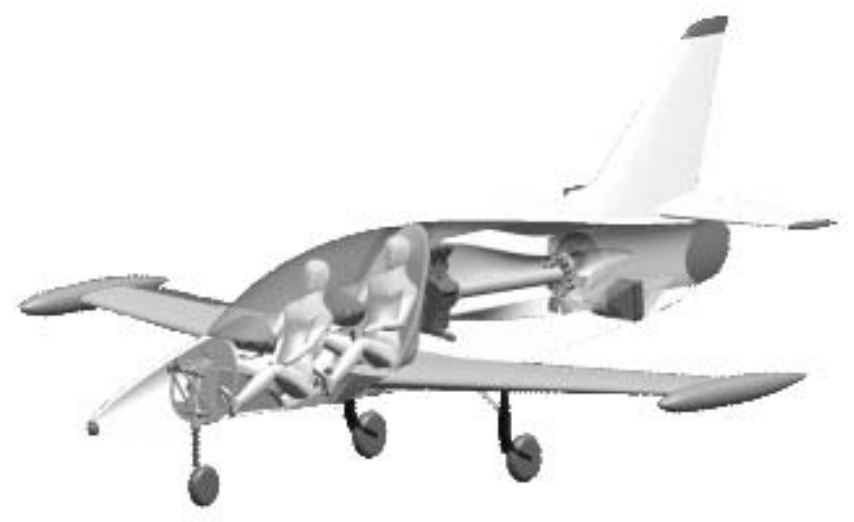

Fig. 2: Accommodation of pilots, engine and fan - 3D CAD model

The thin-walled shaft (Fig. 2) implements the power transmission directly from the engine to the fan.

The ducted fan and the inlet channel are designed to keep a laminar boundary layer. The fan consist of fourteen rotor blades and seven stator blades. The fan with a outlet nozzle provides $1.8 \mathrm{kN}$ effective thrust. According to our calculation, this thrust should be generate to maintain a maximum speed of $300 \mathrm{~km} / \mathrm{h}$. During the landing, a Fowler flap will be used. The landing speed will be $65 \mathrm{~km} / \mathrm{h}$.

\section{The design of the inlet channels (3D model)}

The inlet channel is designed to keep a laminar boundary layer all along the channel length. In this case, the minimum inner energy of the flow will dissipate. Our boundary layer calculation [5] shows that the optimum channel cross-section taper is 0.54 per $1 \mathrm{~m}$ of channel length (Fig. 3). The chord ratio of the inlet channel is 0.64 .

\section{Input data for design:}

1. The outlet cross-section is given by the fan dimensions. These are:

$\begin{array}{ll}\text { inner diameter } & d=0.300 \mathrm{~m} \\ \text { outer diameter } & D=0.580 \mathrm{~m}\end{array}$

2. The shape of the inlet cross section has to fulfill the flow solution and the fuselage design condition.

3. The requirement of minimum curvature of the channel cross-section centroids join curve (minimum secondary flow [4])

4. Smoothness and continuity of the channel chord ratio are the main requirements of channel design. To maintain the laminar boundary layer throughout the length of the channel, it is important to continually downsize the cross-section areas of the channel [2 and 3]. Fig. 4 represents the visual smoothness control of the designed channel and the shape of the channel face curves.

During the development process, more than ten versions of the channel design were made. Some of them are shown in Fig. 5. The first version depicted in Fig. 5 was made fully analytically. However, the analytical solution of this task is very tedious and time consuming. The other channel model versions were made using the Unigraphics professional 3D CAD system. The versions have varying shapes of the leading part, air entrance and the relative position of the fan axis. The aim of all design variants was to achieve the best velocity distribution at the channel exit. The aerodynamic quality of each variant was checked using the fluent by profes-
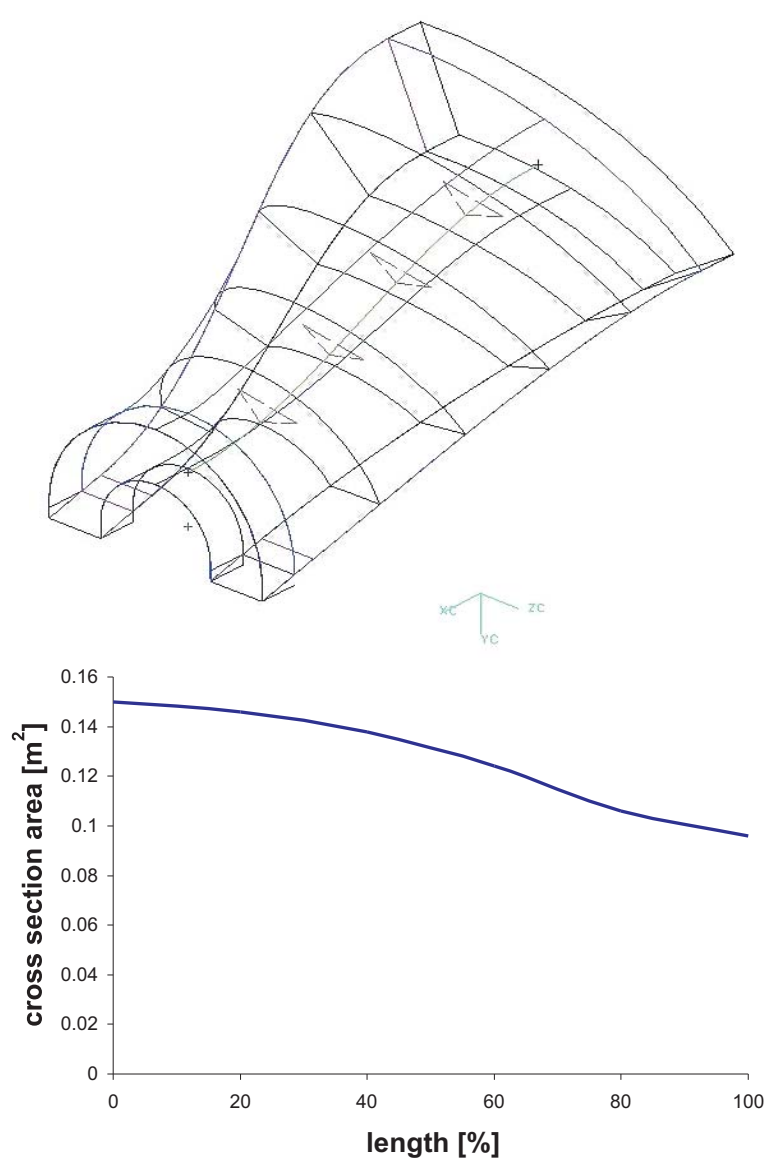

Fig. 3: The channel cross-section layout 


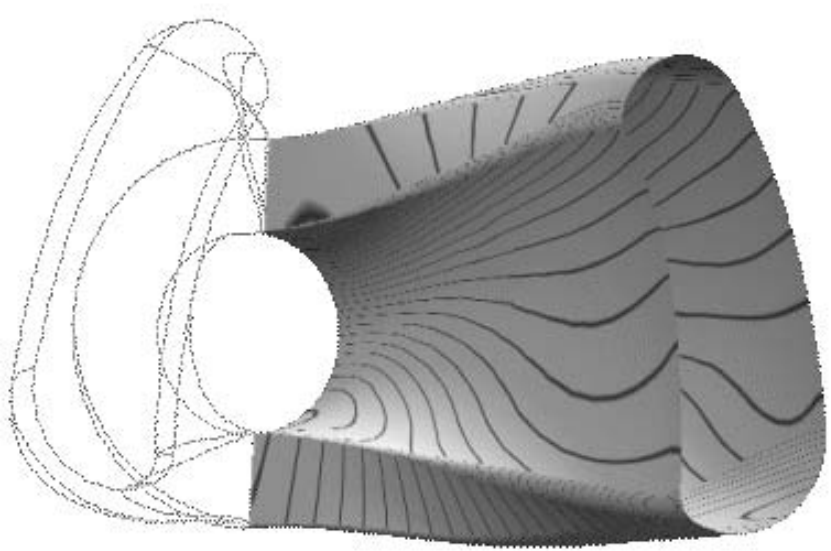

Fig. 4: Visual smoothness control of the channel faces

sional CFD calculation system. For these calculations similar boundary conditions were been used for each design variant. Velocity $w_{1}=50 \mathrm{~m} / \mathrm{s}$ was used as the "inlet velocity", and uniform distribution assumed. For aerodynamic calculations, the incompressible condition of flow was used. The standard model of turbulence k- $\varepsilon 0.2 \%$ turbulence intensity was used.

\section{Description of the presented channel design variants}

Version No. 1: Fully analytical design. The channel has the shape of a diffuser. The velocity distribution is very unsatisfactory. At the bottom of the channel the value of the air flow velocity is about $20 \mathrm{~m} / \mathrm{s}$, while and at the top it is $120 \mathrm{~m} / \mathrm{s}$.

Version No. 5: In this version, the main focus was on the geometrical similarity of the inlet and outlet cross-section shape. The resultant shape of the channel does not correspond to that of a real L-39 airplane. The velocity distribution in the channel has been improved; however, the main flow occurred in the top part of the channel cross-section.

Version No. 10: The shape of the channel cross-section was improved by filleting the corners. The main axis of the fan was moved up. As can be seen in the Fig. 5 the air-flow distribution in the channel is not uniform. There are three areas of

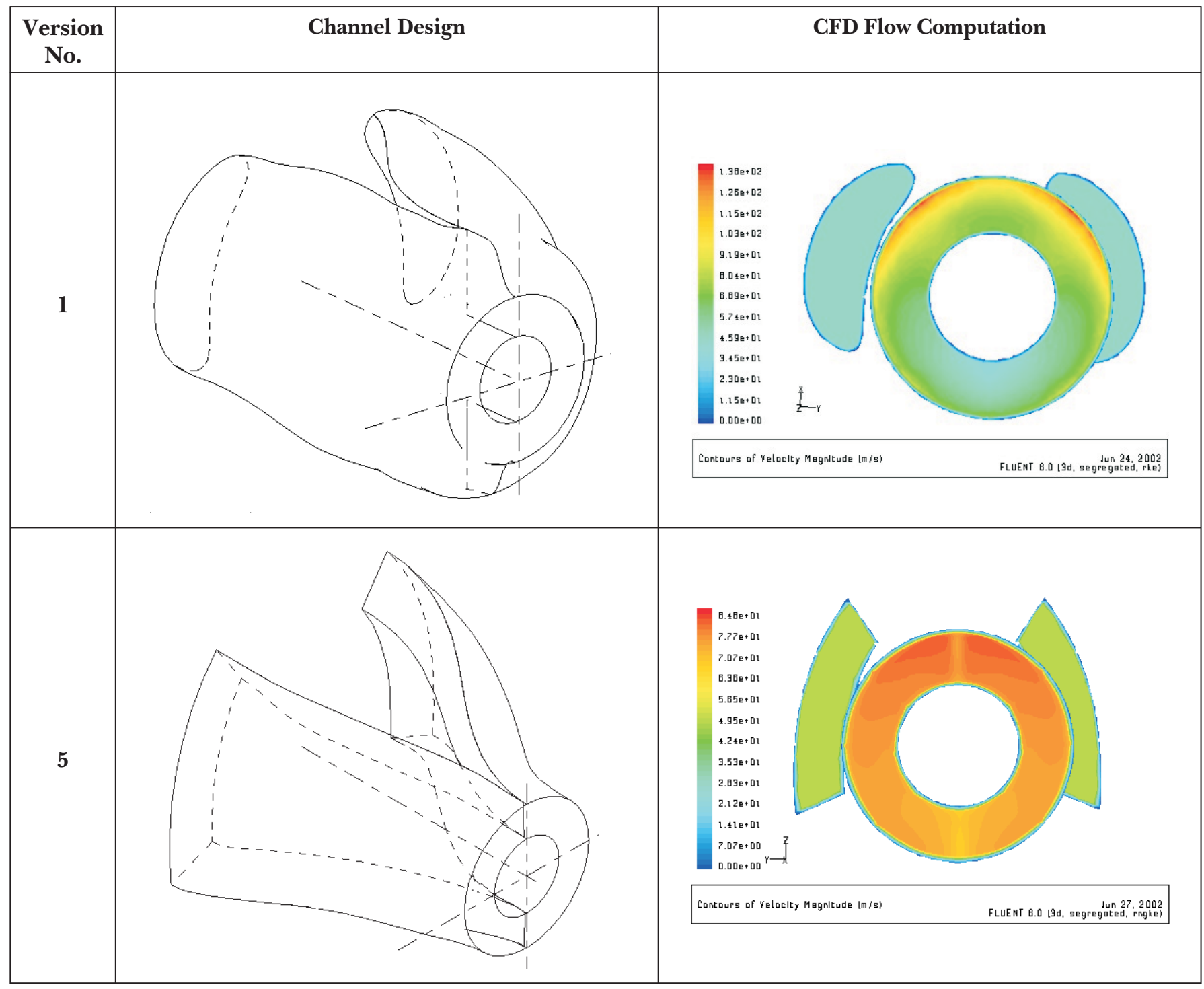




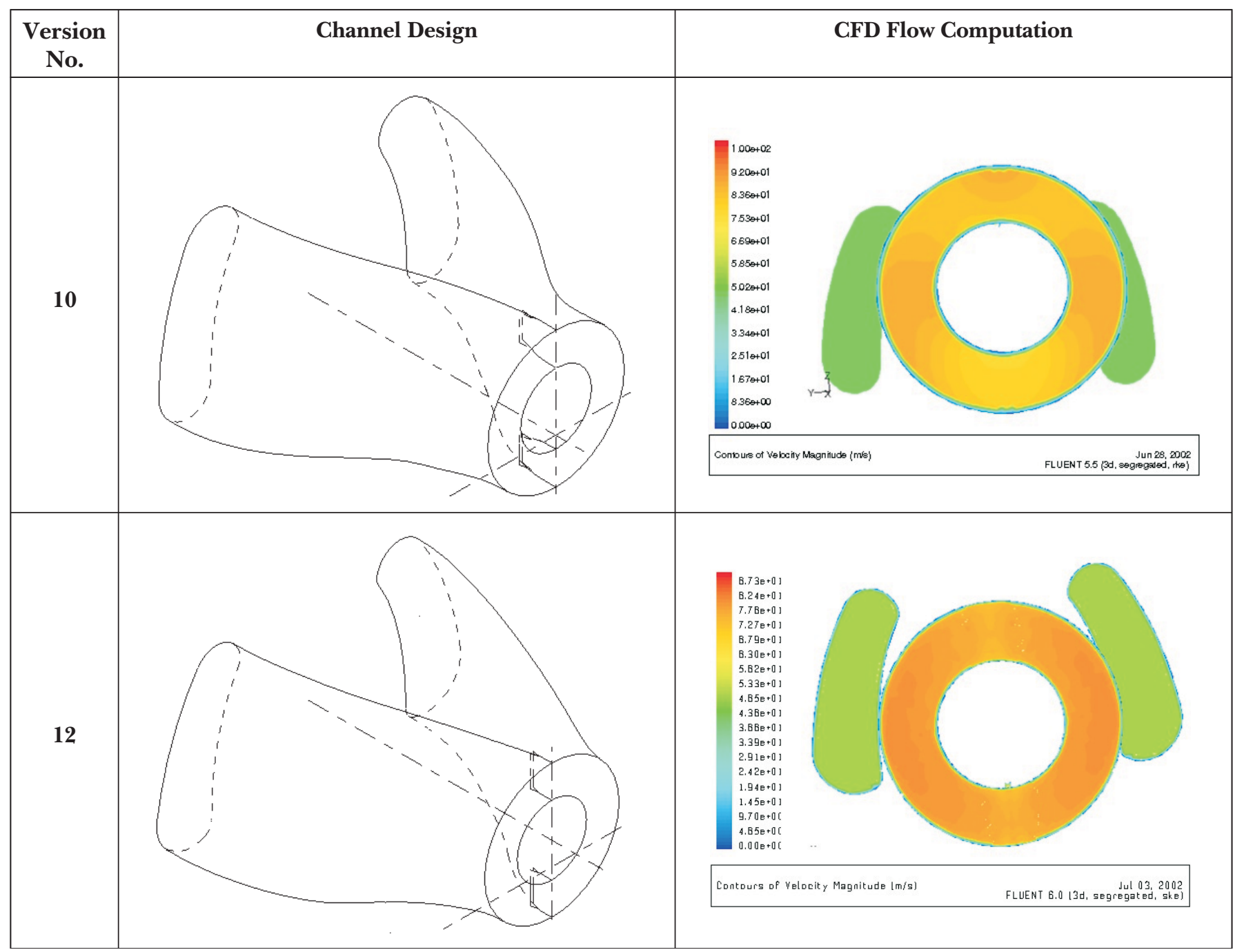

Fig. 5: Some of the design verions of the proposed channel

higher flow velocity. This can negatively influence the stress of the rotor blades.

Version No. 12: The final version. The inlet cross-section has been enlarged in the bottom area. The CFD calculation showed that the flow distribution of this channel is relatively uniform. The velocity in the channel cross section varies by max. $6 \%$ about the mean value of the flow velocity.

\section{Experiment}

The aerodynamic behavior of the final version of the inlet channel design was experimentally tested. For the experimental tests, a model of the proposed channel was made, on a scale of 1:1.934. The model was handmade from glass fiber and a positive form was used. The form itself was made with the use of CAM technology based on a UG model.

The aim of the aerodynamic experiment was to confirm the expected outlet velocity field. The experiment was carried in the wind tunnel of laboratory U 207.1 at CTU in Prague. A five-hole probe was used for investigating the velocity field of the outlet channel. The investigation itself was in two steps.

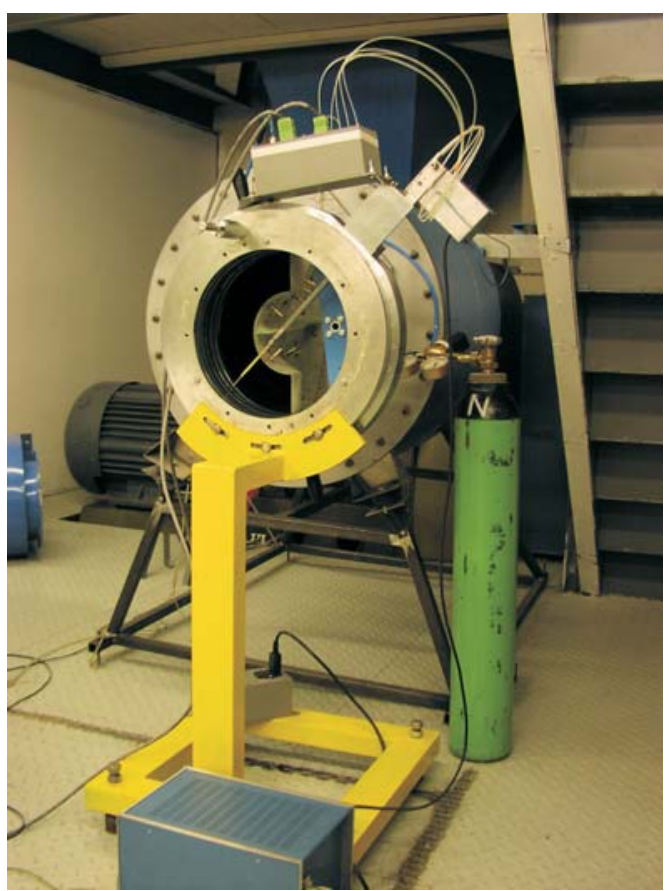

Fig. 6: Experimental measurement of proposed channel 


\section{The comparison of the CFD calculation and the 2D experimental measurement $\operatorname{Re}=4.12 \mathrm{E} 6$}
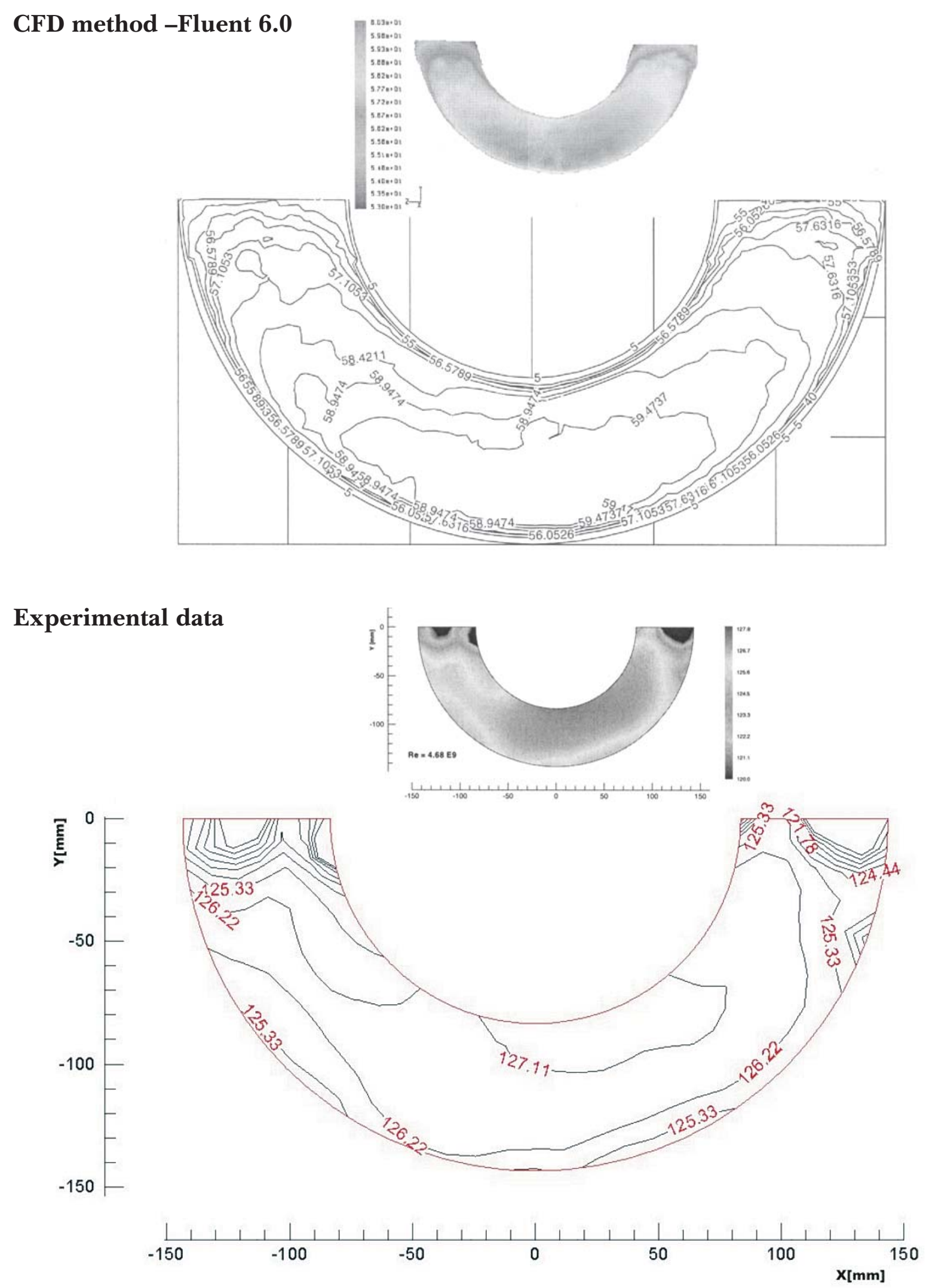

Fig. 7: Comparison of the 2D velocity field data Re 4.12 E6 
In the first step, the 2D outlet velocity field was determined. The probe position setting and data recording are manual. The field is mapped at 250 points.

The second step of the experimental measurement is the mapping of the 3D outlet velocity field. Semiautomatic probe setting and automatic data recording are used for 3D mapping of the flow field, see Fig. 7. Outlet velocity map has about 500 points. The two experimental measurements are now in progress and the data is being evaluated.

\section{Conclusion}

This paper attempts to demonstrate possibility of applying ducted fan in the design of Micro-light or Ultra-light aircraft. However, only our experimental results will prove the accuracy of the calculations presented here. The preliminary results from the experimental test show that the inner dissipation of the flow energy is below 3 percent and that utilization of the "cold jet" propulsion unit is possible.

\section{References}

[1] Marc de Piolenc, F., Wright Jr., G. E.: Ducted Fan Design. 1997, V.1, p. 61-86.

[2] Goldsmith, E., Seddon, J.: Practical Intake Aerodynamic Design AIAA. 1993.
[3] Seddon, J., Goldsmith, E.: Intake Aerodynamics Second Edition AIAA. 1999.

[4] Jerie, J.: Elementare Theorie der Doppelwirbel in Gekrummten Kanalen. Wiss. Zeit. d., TU Dresden, 37, 1988, p. 87-93.

[5] Thwaites, B.: Approximate Calculations of the Laminar Boundary Layer. Aero Quart., 1, 1949, p. 245-280.

Ing. Erik Ritschl

phone: +420224357492

e-mail: erik.ritschl@fs.cvut.cz

Ing. Robert Theiner

phone: +420224357423

e-mail: robert.theiner@fs.cvut.cz

Ing. Daniel Hanus, CSc.

phone: +420224357482

e-mail: daniel.hanus@fs.cvut.cz

Department of Aerospace Engineering

Czech Technical University

Faculty of Mechanical Engineering

Karlovo nám. 13

12135 Prague 2, Czech Republic 